\title{
TRANSFORMAÇÃO DIGITAL: \\ SELEÇÃO DOS FATORES MAIS RELEVANTES ATRAVÉS DO APOIO MULTICRITÉRIO À DECISÃO
}

\author{
Alexandre Thomaz Pereira \\ Ibmec - RJ \\ Avenida Presidente Wilson 118, Rio de Janeiro \\ alexthomaz.pereira@gmail.com \\ Luiz Flavio Autran Monteiro Gomes \\ Ibmec - RJ \\ Avenida Presidente Wilson 118, Rio de Janeiro \\ luiz.gomes@ibmec.edu.br
}

\begin{abstract}
RESUMO
A revolução digital vem promovendo significativa mudança na forma com que vivemos, nos relacionamos e fazemos negócios, fenômeno claramente percebido em todos os segmentos e geografias. Organizações surgidas antes da Internet, especialmente as de médio e grande porte, demonstram hesitação e particular dificuldade para lidar com a disrupção digital, cuja intensidade e alcance não cessam de produzir significativas alterações em cada um dos setores da economia. Uma revisão nos dados públicos do S\&P 500 - considerado um dos principais barômetros do mercado global - no período compreendido entre os anos 2000 e 2017, revela seu impacto e inclemência: menos de 50\% das empresas conseguiram permanecer entre as listadas. É inadiável, pois, uma reflexão mais profunda sobre quais os fatores mais relevantes na condução de uma efetiva Transformação Digital, para que estas organizações possam aprofundar seu entendimento, e propor ações mais efetivas para lidar com o senso de urgência exigido pela economia digital. $O$ pesquisador, com base na literatura disponível sobre o tema, identificou 34 fatores relevantes, e solicitou que experientes consultores de Negócios e de TI os ordenassem a partir de sua adequação e importância para uma bem-sucedida jornada de Transformação Digital. Em seguida, a partir da aplicação de métodos de Apoio Multicritério à Decisão, selecionou os fatores mais relevantes que deveriam capturar a atenção dos executivos responsáveis por Transformações Digitais em empresas que operam no Brasil.
\end{abstract}

Palavra-chave: Transformação Digital; Inovação Digital; Apoio Multicritério à Decisão; Métodos Ordinais.

\begin{abstract}
The digital revolution has promoted a significant change in the way we live, relate and do business, a phenomenon that is clearly perceived in all segments and geographies. Organizations that have emerged before the Internet, especially those of medium and large size, show hesitation and difficulty in dealing with digital disruption, whose intensity and scope are constantly changing in each sector of the economy. A review of the S\&P 500's public data - considered one of the main barometers of the global market - between 2000 and 2017 reveals its impact and inclemency: less than $50 \%$ of companies were able to remain among those listed. A more in-depth reflection on what the most relevant factors in conducting an effective Digital Transformation is, therefore, for these
\end{abstract}


organizations to deepen their understanding and propose more effective actions to deal with the sense of urgency required by the digital economy. Based on available literature, the researcher identified 34 relevant factors and asked experienced Business and IT consultants to order them from their appropriateness and importance for a successful Digital Transformation journey. Then, based on the application of Multicriteria Decision Support methods, it selected the most relevant factors that should capture the attention of executives responsible for Digital Transformations in companies operating in Brazil.

Keywords: Digital Transformation; Digital Innovation; Multicriteria Decision Support; Ordinary Methods.

\section{Como Citar:}

PEREIRA, Alexandre Thomaz; GOMES, Luiz Flavio Autran Monteiro. Transformação digital: seleção dos fatores mais relevantes através do apoio multicritério à decisão. In: SIMPÓSIO DE PESQUISA OPERACIONAL E LOGÍSTICA DA MARINHA, 19., 2019, Rio de Janeiro, RJ. Anais [...]. Rio de Janeiro: Centro de Análises de Sistemas Navais, 2019.

\section{INTRODUÇÃO}

Nas últimas décadas, temas contemporâneos tais como responsabilidade social e consciência ambiental expandiram as prioridades organizacionais para além das tradicionais preocupações com o aumento da produtividade, melhoria da qualidade e satisfação do cliente. Mais recentemente, já no século XXI, devido ao significativo impacto em todos os setores da economia, um novo tópico foi incorporado à esta lista: disrupção digital.

Sua intensidade e inclemência podem ser percebidas no relatório Corporate Longevity Forecast (Innosight, 2018), que analisa dados públicos do ranking S\&P 500 considerado um dos principais barômetros do mercado global - no período compreendido entre os anos 2000 e 2017. O estudo revela que menos de 50\% das empresas conseguiram permanecer entre as listadas, ou seja, a maioria não conseguiu depreender as dimensões deste fenômeno disruptivo e romper com o que "sempre funcionou".

Seja por lentidão ou miopia, as organizações mais penalizadas têm sido aquelas que resistem em examinar o fenômeno digital de maneira holística, preferindo conduzir iniciativas digitais meramente episódicas e tímidas, sucumbindo ao chamado Darwinismo Digital, descrito por Solis (2014) como o fenômeno em que a tecnologia e a sociedade evoluem mais rapidamente do que uma organização pode se adaptar.

A revolução digital está hospedando um novo momento de interseção, semelhante ao que europeus testemunharam durante a Renascença (séculos XV e XVI) - período sem precedentes de descobertas e conquistas em filosofia, pintura, música, escultura, arquitetura e literatura. O termo Renascença significa "renascimento" e formou uma ponte da Idade Média com a Era Moderna. Comparativamente, estamos ganhando admissão na sociedade digital, trazida a nós por muitas tecnologias como o Big Data, Inteligência Artificial, Cloud Computing, Smartphones e Internet das Coisas (IoT) - que estão se unindo para transformar radicalmente a maneira como vivemos e fazemos negócios.

No centro desta revolução estão os consumidores, mais equipados, melhor informados e menos leais às marcas tradicionais. O campo de batalha migrou da loja mais bem localizada no shopping center para a tela de um smartphone (Kiron, 2016). Como resultado, as empresas - especialmente aquelas com certidão de nascimento pré-digital, viram-se forçadas a estar presente nos mais diversos canais e plataformas digitais, conhecer o comportamento e preferencia de seus clientes, visando capturar seu tempo e atenção.

Manterem-se competitivas em um ambiente de constante inovação digital tornou-se 
um imenso desafio para as empresas, especialmente àquelas estabelecidas a mais tempo, e as impõe engajar-se em uma jornada de completa transformação, entretanto, o alvorecer dessa era digital reivindica que as organizações entendam as raízes deste fenômeno, reavaliem seus modelos de negócios, ampliem seus conhecimentos e investimentos sobre futuras demandas, e fortaleçam seus relacionamentos com os Clientes. É inadiável, pois, uma reflexão mais profunda sobre quais os fatores mais críticos e relevantes na condução de uma efetiva Transformação Digital, para que consigam lidar com o aumento da complexidade no processo de tomada de decisão na exigente economia digital. Segundo Gomes et al. (2004), o ato de decidir é uma ação complexa, uma vez que concerne em o que decidir, pois uma decisão equivocada pode incorrer em problemas irreversíveis.

Considerando o grau de complexidade e imaturidade do processo de transformação digital, e o potencial impacto danoso que decisões equivocadas podem produzir nas organizações, este estudo avalia os desafios enfrentados na digitalização de empresas de médio e grande porte no Brasil, e utilizando métodos multicritério ordinais, tem por objetivo elencar os fatores mais relevantes para que esta inexorável jornada possa ser conduzida com maior precisão e alcance resultados mais efetivos.

\section{REFERENCIAL TEÓRICO}

\subsection{TRANSFORMAÇÃO DIGITAL}

Segundo Khan (2016), para definir transformação digital é necessário antes estabelecer o conceito de digital e digitalização. O digital está associado ao processo de conversão de informação analógica em formato digital, enquanto a digitalização está relacionada à questão de transformar os processos físicos em processos virtuais utilizando-se tecnologias específicas para tal.

De acordo com Pagani e Pardo (2017), a transformação digital, também chamada de “digitalização", é um fenômeno social ou evolução cultural, e para as empresas é tido como uma evolução ou criação de modelo de negócio. Neste contexto, segundo Henriette et al. (2016), as empresas devem ser capazes de se adaptar mudando seu modelo de negócios ou desenvolvendo um novo modelo.

De acordo com Collin et al. (2015), a transformação digital não se limita a adoção de novas tecnologias, mas também de novas maneiras de tornar os negócios mais eficientes e competitivos. Para Birkinshaw e Zimmermann (2016), é um processo de mudança no qual as organizações questionam seus processos básicos, tecnologias e modelos de negócios, avaliando e melhorando a coleta, análise e transferência de dados ao longo da cadeia de valor.

Henriette et al. (2016), propõem definir a transformação digital como "um processo de mudança disruptiva ou incremental, que começa com a adoção de tecnologias digitais, evoluindo para uma transformação holística implícita de uma organização ou deliberada para buscar a criação de valor ".

\subsection{DIMENSÕES E FATORES DA TRANSFORMAÇÃO DIGITAL}

De acordo com Hess et al. (2016), uma estratégia de transformação digital deve abordar os possíveis efeitos nas interações entre as fronteiras da empresa com clientes, concorrentes e fornecedores, e propõem um framework para planejar uma jornada de transformação digital, composto de quatro dimensões:

1. Tecnologia: Visa entender a importância da TI da empresa para atingir as metas estratégicas.

2. Criação de Valor: Objetiva identificar até que ponto sua empresa deve diversificar seus negócios para o mundo digital e como gerará novas receitas, ou seja, o quanto "digital” deve ser a interface com o cliente. 
3. Mudanças Estruturais: Começa com a identificação do executivo responsável pela condução do processo de transformação digital dentro da empresa, passando pela definição se desejam integrar as novas operações digitais em suas estruturas atuais ou organizá-las como unidades distintas e separadas.

4. Financeira: Conhecer a intensidade da pressão financeira e a competitividade do negócio atual da empresa para calibrar a disposição da alta administração de embarcar em uma jornada de transformação digital.

Rogers (2016), considera que a Transformação Digital deve ser concebida a partir de cinco principais domínios:

1. Clientes: Não devem mais ser percebidos como mercado de massa. Passam a ser uma rede dinâmica, onde a comunicação flui em mão dupla.

2. Competição: Deixa de ocorrer em setores delimitados, e passa a existir entre diferentes setores - com distinções nebulosas entre parceiros e rivais.

3. Dados: Passam a ser gerados continuamente, em todos os lugares, estruturados e não estruturados, onde o desafio passa a ser convertê-los em informações valiosas.

4. Inovação: Os testes de ideias deixaram de ser caros, lentos e difíceis. Os experimentos passam a ser contínuos, com foco em produtos de viabilidade mínimo, e os fracassos são vistos como fonte barata de aprendizado.

5. Valor: A proposta de valor deixa de ser definida pelo setor e passa a ser estabelecida pela evolução da necessidade dos clientes. Focando em descobrir a próxima oportunidade de criar valor para o cliente.

Segundo Azhari et al. (2014), o processo de transformação digital deve concentrarse em oito dimensões para garantir que esta ocorra integralmente na organização, conforme explícito na Figura 1.

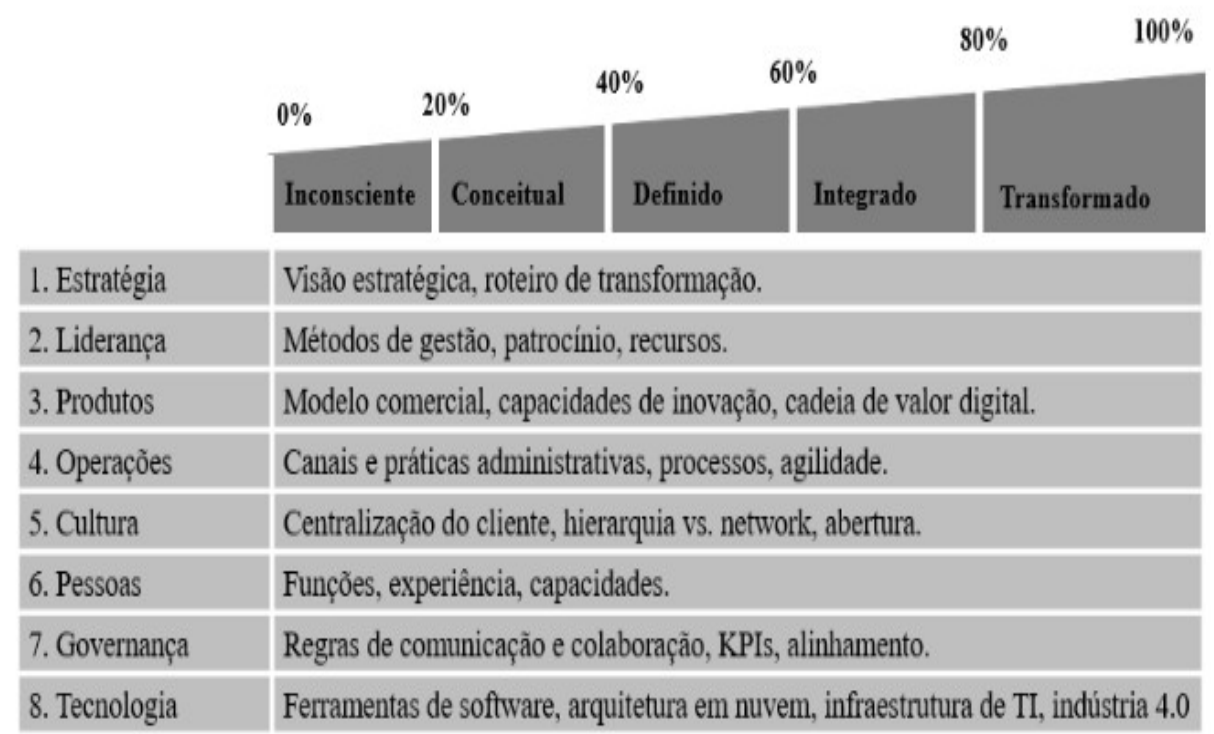

Figura 1 - Dimensões necessárias para condução de um processo de Transformação Digital (Fonte: Azhari et al., 2014)

Para Holotiuk e Beimborn (2017), a transformação digital é um conceito emergente sobre a intersecção de TI e Gestão Estratégica de Negócio, e sua elaboração deve conter oito áreas, conforme descrito abaixo:

1. Vendas e Experiência do Cliente: Para oferecer uma experiência perfeita ao cliente, é necessário integrar todos os canais de comunicação offline (físicos) e on-line (digitais).

2. Organização: Se concentra na agilidade para realocar recursos e reorganizar 
rapidamente. A agilidade é parte integrante da estratégia, exigindo que as empresas consigam ajustar-se a mudanças do ambiente competitivo.

3. Cultura e Liderança: Tem como objetivo fomentar uma mentalidade digital em que a cultura assuma um caráter exploratório e adaptativo, propício a transformação digital. A colaboração e trabalho multifuncional devem ser incentivados a gerar novas ideias e impulsionar a inovação. As empresas estão se libertando do pensamento de silo (verticalizado).

4. Capacidades e Competências de RH: Baseia-se fortemente na capacidade de reinventar a cadeia de valor e desafiar o status quo, onde os funcionários consigam mover-se do mundo tradicional de cadeias de valor para o mundo das plataformas e ecossistemas integrados.

5. Visão: É o estabelecimento de uma visão sobre seu posicionamento futuro e ainda fornecer a clareza necessária para alcançá-la.

6. Dados e TI: Fazer uso de dados (estruturados e não estruturados; internos ou de fontes externas), e dar sentido e significado a eles passa a ser vital para o aprimoramento e continuidade do negócio.

7. Operações: Criação de processos digitalmente automatizados, permitindo, por exemplo, que as cadeias de suprimentos reajam rapidamente e antecipem a demanda do cliente.

8. Parceiros: Possuir sistemas abertos que permitam integração de parceiros, para aumento de valor com cada novo cliente adicionado.

A cultura organizacional deve ser uma das prioridades no processo de transformação digital. É a dimensão que permite que as empresas avancem e consigam uma real transformação. Segundo Piccinini et al. (2015), organizações maduras, com cultura há muito estabelecida, terão maior dificuldade para que seus colaboradores se sintam seguros e considerem eventuais falhas como algo aceitável.

Moreno Jr. et al. (2009), em sua revisão da literatura sobre alinhamento entre TI e negócio, indicam que o alinhamento das áreas de TI e de negócios, quando baseado em estratégias apropriadas, tende a gerar diversos benefícios para uma organização, inclusive vantagem competitiva.

A Governança Corporativa surge como outro potencial entrave no processo de digitalização. Segundo Valentine e Stewart (2015), Conselhos de Administração que não moldam efetivamente seu futuro digital, o investimento e o risco de tecnologia de negócios podem ter um futuro incerto. Isso ocorre porque investimentos inadequados, descoordenados ou inadequados que resultam da falta de competência em liderança digital, podem aumentar significativamente o risco fiduciário, de desempenho e de conformidade.

Holotiuk e Beimborn (2017), propõem uma lista de 40 Fatores Críticos de Sucesso, que devem ser considerados durante um processo de transformação digital, conforme detalhado na Tabela 1. 


\begin{tabular}{|c|c|c|c|}
\hline$\#$ & Dimensão: Vendas e Experiência do Cliente & $\#$ & Dimensão: Organização \\
\hline 1 & Integração dos canais offline (fisicos) e online (digitais) & 7 & Agilidade para realocar recursos e se reorganizar \\
\hline 2 & Digitaliazação da interação de Clientes e de produtos \& serviços & 8 & Change Management para mudanças rápidas e radicais \\
\hline 3 & Analytics para customizar e criar produtos \& serviços & 9 & Organização com diversos niveis para reagir com rapidez \\
\hline 4 & Contato direto: customer centricity & 10 & Alinhamento organizacional em ser digital \\
\hline 5 & Integração do Cliente com inovação aberta & 11 & Orientação de longo-prazo mas com foco em mudanças intensas e curtas \\
\hline \multirow[t]{2}{*}{6} & Excepcional satisfação e experiência do Cliente & 12 & Separação organizacional (digital e não digital) \\
\hline & & 13 & Tomada de decisão simples e enxuta (lean) \\
\hline$\#$ & Dimensão: Cultura e Liderança & $\#$ & Dimensão: Capacidades e Competências de RH \\
\hline 14 & Criar e fomentar mentalidade digital & 20 & Capacidade de reinventar cadeia de valor e questionar status-quo \\
\hline 15 & Conjunto comum de valores com geração de valor a partir do digital & 21 & Talentos e habilidades digitais \\
\hline 16 & Aceitar falhas e encorajar novas tentativas & 22 & Capcidade de desenhar novos modelos de negócios \\
\hline 17 & Cultura de inovação e adaptada aos objetivos & 23 & Novos ativos e capacidades \\
\hline 18 & Compromisso para transformar a estratégia e a cultura & 24 & Lideres devem identificar profissionais com potencial \\
\hline 19 & Repensar os papéis de $\mathrm{ClO}$ e CDO & 25 & Buscar, reter e atrair novoc talentos \\
\hline$\#$ & Dimensão: Perspectiva e Visão & $\#$ & Dimensão: Dados e Tecnologia da Informação \\
\hline 26 & Estabelecer visẫo clara sobre posicionamento futuro & 31 & Uso de dados e informaçāo de fonte centralizada/consolidada \\
\hline 27 & Processo rigoroso de feedback e desejo de melhorar & 32 & Organização de TI com duas velocidades (legado e digital) \\
\hline 28 & Fomentar rapidez de inovaçāo e rápida prototipação & 33 & Capacidade para processar grandes volumes de dados em tempo real \\
\hline 29 & Perceber o que está acontecendo "a esquerda e a direita" & 34 & Plataforma de TI modularizada \\
\hline 30 & Ousadia para experimentar & & \\
\hline$\#$ & Dimensão: Operações & $\#$ & Dimensão: Parcerias \\
\hline 35 & Data-driven and processos digitalmente automatizados & 39 & Efeito Rede através de sistemas abertos e integração de parceiros \\
\hline 36 & Mudança no modelo de operacão (não apenas no de negócios) & 40 & Parceiros Externos \\
\hline 37 & Misturar recursos humanos e digitais & & \\
\hline 38 & Prover recursos financeiros & & \\
\hline
\end{tabular}

Tabela 1 - Dimensões e Fatores Críticos de Sucesso Identificados na Análise das Indústrias e Setores (Fonte: Holotiuk,

\subsection{MÉTODOS MULTICRITÉRIO DE APOIO À DECISÃO}

De acordo com Roy e Bouyssou (1993), o Apoio Multicritério à Decisão (AMD) surgiu como um ramo da Pesquisa Operacional e consiste em um conjunto de métodos e técnicas para auxiliar a tomada de decisão em relação a um grupo de alternativas, quando da presença de critérios múltiplos. Alternativas e critérios devem possuir certas propriedades: alternativas devem ser diferentes, exaustivas e excludentes entre si; critérios devem ser exaustivos, coerentes e não redundantes.

O AMD pode ser definido como o conjunto de técnicas usadas para investigar um número de alternativas, sob múltiplos critérios e objetivos em conflito. Visa apoiar o processo decisório, por meio de indicação de ações ou cursos de ações a serem seguidos (Gomes e Gomes, 2014).

Segundo Soares de Mello (2002), o AMD surgiu formalmente na década de 1970, embora alguns métodos elementares já existiam desde a revolução francesa. Datam dessa época os métodos ordinais de Borda e Condorcet, considerados os precursores das duas grandes escolas de estudo dos métodos multicritérios, a saber:

- A escola norte-americana, que pressupõe a condição do decisor de obter uma concepção exata sobre a utilidade dos "scores" de cada alternativa, e dos pesos de cada critério, com uma metodologia baseada na análise hierárquica dos dados. 
- A escola francesa (ou europeia, ou não compensatória) baseia sua ênfase nas limitações da objetividade do decisor. Desta forma, as preferências não são tão aparentes para este, cabendo ao pesquisador construir um modelo para julgamento de valor, buscando hipóteses de trabalho para fazer recomendações.

\subsection{MÉTODOS DE ORDENAÇÃO}

Como observaram Cook e Seiford (1982), os métodos de ordenação ou ranqueamento podem ser colocados em duas categorias básicas: métodos cardinais e métodos ordinais. Os métodos cardinais exigem que os tomadores de decisão expressem seu grau de preferência de uma alternativa em detrimento de outra para cada critério. Por outro lado, os métodos ordinais exigem apenas que a ordem de classificação das alternativas seja conhecida para cada critério.

Para Larichev e Moshkovich (1995), quando o decisor tem dificuldade em dar uma estimativa numérica precisa para os diferentes parâmetros a serem analisados, é melhor analisar usando-se o julgamento ordinal. Na literatura são encontradas referências a três métodos multicritério ordinais: métodos de Borda, Condorcet e Copeland.

O método de Borda é, em sua essência, uma soma de postos. Tem a grande vantagem da simplicidade. No entanto, apesar do amplo uso de suas variações, o método não respeita um dos mais importantes axiomas de Arrow, o da independência em relação às alternativas irrelevantes (Soares de Mello et al., 2005b).

O método de Condorcet é chamado de "voto da maioria simples", pois trabalha com relação de superação. É considerado mais justo que o de Borda, porém tem a desvantagem de consumir muito tempo para tratar todas as combinações, além de conduzir a situações de intransitividade, levando ao célebre "paradoxo de Condorcet”. O vencedor é o candidato que mais vence os concorrentes numa competição por pares (Saari e Donald, 2001).

O método de Copeland é derivado do método de Condorcet, iniciando-se com a mesma comparação por pares, em que uma alternativa pode vencer ou empatar com outra. $\mathrm{O}$ método soma as vitórias (e empates) e subtrai as derrotas de cada alternativa, ordenando as alternativas de acordo com esse resultado (Barba-Romero e Pomerol, 1997).

\section{METODOLOGIA DE PESQUISA}

A partir da revisão da literatura, compôs-se uma lista preliminar com 27 fatores relevantes - sem a pretensão de ser uma lista exaustiva, tendo em vista o caráter exploratório do estudo. Em seguida, solicitou-se à três experts em Transformação Digital, que utilizassem seus conhecimentos para revisá-la que decidiram por incluir 7 novos fatores.

Na sequência, o pesquisador juntou-se ao grupo de experts, e passaram a avaliar como agrupar os 34 fatores. Partiram de onze opções identificadas na literatura utilizada: Estratégia, Governança, Liderança, Cultura, Organização, Pessoas, Produtos, Clientes, Inovação, Tecnologia e Operações. Pouco mais de uma hora de argumentos e contraargumentos foi suficiente para concluir que as dimensões Organização, Produtos, e Governança estavam compreendidas e representadas pelas dimensões Cultura, Liderança e Inovação, chegando-se, portanto, a oito categorias ou dimensões. A Tabela 2 apresenta os 34 fatores finais a serem ranqueados, já agrupados nas 8 categorias. 


\begin{tabular}{|c|c|c|}
\hline Fator & Categoria & Descrição do Fator \\
\hline 1 & Cultura & Ambiente organizacional encoraja experimentação, tomada de riscos e aceita falhas (fail-fast / try\&learn) \\
\hline 2 & & Organização fomenta mentalidade digital como parte da rotina de trabalho (agenda digital, atuação nas mídias socias) \\
\hline 3 & & Organização data-driven: Tomada de decisão baseada nos dados \\
\hline 4 & & Efetiva colaboração entre Funcionários, Setores \& Departamentos (trabalho mais horizontal/menos silos) \\
\hline 5 & Cliente & Foco em Customer Experience (CX): Cliente é a prioridade, centro e razão do negócio \\
\hline 6 & & Integração dos canais (online/offline) para oferecer abordagem omni-channel aos clientes \\
\hline 7 & & Uso de Analytics para melhor conhecimento sobre preferencias e comportamento dos Clientes \\
\hline 8 & & Digitalização da interação com os Clientes (mudança na forma de interface com o cliente) \\
\hline 9 & Inovação & Ferramentas e métodos para acelerar Inovação e Desenvolvimento de novos produtos \& serviços (prototipação, agile, MVP) \\
\hline 10 & & Organização aberta para identificar novas formas de geração de receita \\
\hline 11 & & Processo ativo de Gestão de inovação (geração, captação, seleção de ideias, recompensa) \\
\hline 12 & & Oferecer produtos e serviços de valor reconhecido e a preços competitivos \\
\hline 13 & Liderança & Conselho de Administração com experiência e visão sobre negócios digitais \\
\hline 14 & & $\mathrm{CIO}$ mais estratégico - maior envolvimento, alinhamento e trânsito de $\mathrm{TI}$ com as áreas de negócios \\
\hline 15 & & CEO Comprometido - percebido como principal patrocinador das transformaçōes organizacionais \\
\hline 16 & & Alta e média gerência com ativa participacao e engajamento digital \\
\hline 17 & Operações & Maior autonomia e agilidade no processo decisório (descentralização na alocação de recursos financeiros, técnicos e humanos) \\
\hline 18 & & Processos de negócios reconfigurados e automatizados para reagir com maior agilidade (responder à demandas de mercado) \\
\hline 19 & & Cadeia de Suprimentos bem qualificada, orquestrada e ágil (fornecedores e parceiros com experiencia digital) \\
\hline 20 & & Operação de TI Bi-modal com distintos focos: iniciativas digitais \& sistemas legados \\
\hline 21 & & Indicadores de Performance (KPIs) do negócio são conhecidos \& monitorados adequadamente \\
\hline 22 & Pessoas & Possuir expertise digital (identifica e elimina gaps de competencias/skills) \\
\hline 23 & & Atrair e reter novos talentos com habilidades digitais (internos e externos) \\
\hline 24 & & Processo de Change Management para suportar as etapas da Transformação Digital \\
\hline 25 & & Colaboradores entendem clara e objetivamente os direcionamentos organizacionais e resultados esperados \\
\hline 26 & Estratégia & Visão clara sobre o posicionamento futuro da organização \\
\hline 27 & & Modelo de negócios revisado/ajustado para competir digitalmente \\
\hline 28 & & Investimentos e recursos necessários são conhecidos e estão orçados \\
\hline 29 & & Conhece e monitora o mercado e os principais competidores (incumbentes/startups) \\
\hline 30 & & Dispōe de Roadmap para conduzir/nortear sua Transformação Digital \\
\hline 31 & Tecnologia & Disponibilização e difusão de novas tecnologias necessárias para competir no ambiente digital (Big Data, Cloud, Al, etc) \\
\hline 32 & & Integração de dados dos principais sistemas organizacionais (baixa latência) \\
\hline 33 & & Infraestrutura flexivel, escalável e de alta disponibilidade \\
\hline 34 & & Mecanismos para garantir proteção e segurança dos dados dos Clientes \\
\hline
\end{tabular}

Tabela 2 - Lista final dos 34 fatores agrupados pelas 8 categorias ou dimensões

Após estas etapas, elaborou-se instrumento de pesquisa de campo com a finalidade de obter o ranqueamento (ordenação) dos fatores por cada um dos 10 respondentes convidados. Como dito anteriormente, quando se deseja saber qual é a melhor alternativa para um dado critério, qual a segunda melhor, e assim por diante, sendo o peso exato de cada critério desconhecido, está se fazendo uso de métodos ordinais, ou quando o decisor tem dificuldade em dar uma estimativa numérica precisa para os diferentes parâmetros a serem analisados, é melhor analisar usando-se o julgamento ordinal. Cada um dos respondentes atribuiu o \#1 à alternativa que julgou a mais relevante, o \#2 à segunda mais relevante, e assim sucessivamente para todos os 34 fatores.

O pesquisador optou por aplicar os três métodos de ordenação (Borda, Condorcet e Copeland), e conduzir posterior análise comparativa dos resultados por eles produzidos. Conforme destacaram Gomes e Costa (2015), a opção de utilizar mais de um método não é fazer uma comparação axiomática entre os métodos, mas apresentar ao decisor os resultados obtidos pela aplicação de diferentes métodos multicritério como forma de oferecer maior suporte ao processo decisório.

Os dados dos respondentes foram processados pelo programa chamado Web PROA (PReferências Ordinais Agregadas), desenvolvido em linguagem Java, que implementa três métodos AMD: o Método de Borda, de Condorcet e de Copeland. 


\section{ANÁLISE DOS RESULTADOS}

De posse das respostas enviadas pelos 10 respondentes da pesquisa, os dados foram inseridos no programa Web PROA para que os rankings fossem gerados a partir de cada um dos três métodos AMD. A Tabela 3 apresenta a ordenação consolidada feita pelos profissionais convidados, onde o respondente $\mathrm{MV}$, por exemplo, considerou que os fatores 15 e 26 como os mais relevantes, atribuindo-os, respectivamente, as notas 1 e 2.

\begin{tabular}{|c|c|c|c|c|c|c|c|c|c|c|}
\hline $\begin{array}{l}\text { Respondentes } \\
\text { FATORES }\end{array}$ & MV & AP & $A 6$ & PJ & NM & MS & $\mathrm{RL}$ & $\mathrm{RN}$ & CA & MR \\
\hline 1 & 7 & 15 & 29 & 12 & 15 & 20 & 1 & 16 & 6 & 19 \\
\hline 2 & 12 & 16 & 29 & 21 & 29 & 31 & 5 & 29 & 29 & 29 \\
\hline 3 & 8 & 10 & 10 & 29 & 19 & 3 & 26 & 17 & 3 & 12 \\
\hline 4 & 26 & 9 & 3 & 11 & 27 & 14 & 15 & 15 & 20 & 22 \\
\hline 5 & 4 & 12 & 3 & 9 & 1 & 2 & 27 & 3 & 1 & 1 \\
\hline 6 & 21 & 17 & 22 & 10 & 25 & 32 & 32 & 21 & 26 & 11 \\
\hline 7 & 28 & 19 & 20 & 31 & 8 & 13 & 6 & 22 & 21 & 13 \\
\hline 8 & 22 & 18 & 30 & 30 & 25 & 19 & 29 & 4 & 9 & 27 \\
\hline 9 & 17 & 20 & 34 & 14 & 30 & 12 & 11 & 28 & 7 & 14 \\
\hline 10 & 9 & 13 & 23 & 13 & $\theta$ & 7 & 2 & 27 & 27 & 23 \\
\hline 11 & 27 & 14 & 27 & 28 & 3 & 21 & 3 & 24 & 31 & 2 \\
\hline 12 & 25 & 27 & 33 & 33 & 25 & 28 & 25 & 10 & 85 & 28 \\
\hline 13 & 28 & 24 & 2 & 32 & 34 & 27 & 30 & 25 & 10 & 34 \\
\hline 14 & 10 & 25 & 7 & 20 & u & 5 & 13 & 14 & 16 & 3 \\
\hline 15 & 1 & 6 & 4 & 1 & 2 & 1 & 4 & 2 & 2 & 15 \\
\hline 16 & 3 & 7 & 9 & 2 & 21 & 22 & 7 & 8 & 19 & 33 \\
\hline 17 & 13 & 22 & 14 & 26 & 313 & 16 & 16 & 19 & 32 & 20 \\
\hline 11 & 16 & 21 & 15 & 7 & 22 & 10 & 8 & 12 & 24 & 21 \\
\hline 19 & 19 & 26 & 21 & 27 & 12 & 26 & 17 & 11 & 28 & 31 \\
\hline 20 & 24 & 23 & 17 & 8 & 13 & 34 & 31 & 6 & 15 & 32 \\
\hline 21 & 14 & 8 & 19 & 34 & 23 & 4 & 26 & 29 & 18 & 26 \\
\hline 22 & 33 & 30 & 13 & 24 & 14 & 11 & 33 & 7 & 11 & 16 \\
\hline 23 & 31 & 29 & 12 & 25 & 15 & 17 & 18 & 13 & 39 & 8 \\
\hline 24 & 20 & 28 & 13 & 16 & 31 & 20 & 19 & 5 & 3 & 17 \\
\hline 25 & 6 & 11 & 16 & 17 & 29 & 29 & 20 & 21) & 23 & 30 \\
\hline 26 & 2 & 1 & 1 & 3 & $w$ & 30 & 9 & 25 & 4 & 4 \\
\hline 27 & 5 & 2 & 5 & 4 & 11 & 9 & 34 & 1 & 5 & 5 \\
\hline 21 & 29 & 5 & 6 & 16 & 5 & 16 & 21 & 32 & 14 & 18 \\
\hline 20 & 50 & 4 & 11 & 19 & 12 & 25 & 10 & 8 & 22 & 6 \\
\hline 30 & 11 & 3 & $B$ & 5 & 3 & 4 & 22 & 33 & 13 & 7 \\
\hline 31 & 2 & 33 & 23 & 22 & 4 & 1 & 12 & 34 & 12 & 9 \\
\hline 32 & 27 & 34 & 31 & 6 & 24 & 30 & 14 & 31 & 30 & 24 \\
\hline 33 & 16 & 32 & 25 & 15 & 17 & 23 & 23 & 32 & $\frac{3}{8}$ & 25 \\
\hline 34 & 15 & 31 & 24 & 23 & 6 & 15 & 24 & 34 & 17 & 10 \\
\hline
\end{tabular}

Tabela 3 - Resumo da ordenação dos fatores feita por cada um dos 10 respondentes

\subsection{Aplicando o Método de Borda}

Como dito anteriormente, o método de Borda ordena as alternativas através da soma dos pontos obtidos em cada uma delas, e aquela que obtiver menos pontos será considerada a melhor ranqueada e a que tiver mais pontos, ficará em último lugar no ranking.

\subsection{APLiCAndo o MÉTOdo de CONDORCET}

O método de Condorcet trabalha com relação de superação, e a alternativa mais bem ranqueada é a que mais vence os concorrentes numa comparação par-a-par. $\mathrm{O}$ programa Web PROA indicou que o fator 15 foi o mais bem classificado, entretanto informou que "Não foi possível classificar todas as alternativas, pois ocorreu um ciclo de intransitividade” (situação conhecida como “Tripleta de Condorcet”).

\subsection{Aplicando o Método de Copeland}

O método de Copeland sempre produz o mesmo resultado de Condorcet, quando este não apresenta nenhum ciclo de intransitividade. Calcula a soma das vitórias menos as derrotas, em uma votação por maioria simples, e então ordena as alternativas pelo resultado da soma. 


\begin{tabular}{|c|c|c|c|c|c|c|}
\hline \multirow{2}{*}{ RANKING } & \multicolumn{3}{|c|}{ BORDA } & \multicolumn{3}{|c|}{ COPELAND } \\
\hline & FATOR & DIMENSAO & PONTUACAAO & FATOR & CATEGORIA & PONTUACÁO \\
\hline 1 & 15 & Liderança & 38 & 15 & Liderança & 33 \\
\hline 2 & 5 & Cliente & 63 & 5 & Cliente & 30 \\
\hline 3 & 27 & Estratégia & 81 & 26 & Estratégia & 29 \\
\hline 4 & 26 & Estratégia & 89 & 27 & Estratégia & 27 \\
\hline 5 & 30 & Estratégia & 109 & 30 & Estratégia & 24 \\
\hline 6 & 14 & Liderança & 131 & 1 & Cultura & 18 \\
\hline 7 & 16 & Liderança & 131 & 14 & Liderança & 17 \\
\hline 8 & 1 & Cultura & 137 & 16 & Liderança & 17 \\
\hline 9 & 3 & Cultura & 139 & 3 & Cuitura & 14 \\
\hline 10 & 29 & Estratégia & 149 & 29 & Estratégia & 14 \\
\hline 11 & 10 & Inovação & 158 & 28 & Estratégia & 12 \\
\hline 12 & 18 & Operaçōes & 158 & 18 & Operaçōes & 9 \\
\hline 13 & 28 & Estratégia & 163 & 10 & Inovaçāo & 7 \\
\hline 14 & 31 & Tecnologia & 174 & 31 & Tecnologia & 6 \\
\hline 15 & 7 & Cliente & 176 & 7 & Cliente & 2 \\
\hline 16 & 11 & Inovaçâo & 184 & 9 & Inovaçâo & -3 \\
\hline 17 & 9 & Inovaçăo & 187 & 21 & Operaçōes & -4 \\
\hline 18 & 4 & Cultura & 191 & 22 & Pessoas & -4 \\
\hline 19 & 22 & Pessoas & 193 & 4 & Cultura & -5 \\
\hline 20 & 21 & Operaçōes & 194 & 11 & Inovaçăo & -7 \\
\hline 21 & 34 & Tecnologia & 199 & 23 & Pessoas & -8 \\
\hline 22 & 20 & Operaçōes & 203 & 25 & Pessoas & -8 \\
\hline 23 & 23 & Pessoas & 203 & 34 & Tecnologia & -8 \\
\hline 24 & 25 & Pessoas & 204 & 20 & Operaçōes & -9 \\
\hline 25 & 8 & Cliente & 208 & 17 & Operaçōes & -10 \\
\hline 26 & 17 & Operaçōes & 211 & 6 & Cliente & -14 \\
\hline 27 & 24 & Pessoas & 214 & 8 & Cliente & -15 \\
\hline 28 & 33 & Tecnologia & 216 & 24 & Pessoas & -16 \\
\hline 29 & 6 & Cliente & 218 & 33 & Tecnologia & -16 \\
\hline 30 & 2 & Cultura & 229 & 2 & Cultura & -18 \\
\hline 31 & 19 & Operaçōes & 238 & 19 & Operaçōes & -24 \\
\hline 32 & 13 & Liderança & 248 & 12 & Inovaçâo & -29 \\
\hline 33 & 32 & Tecnologia & 254 & 13 & Liderança & -30 \\
\hline 34 & 12 & Inovaçāo & 259 & 32 & Tecnologia & -31 \\
\hline
\end{tabular}

Tabela 4 - Resultado da ordenação dos 34 fatores utilizando os métodos de Borda e Copeland

A Tabela 4 apresenta o ranking feito pelo Web PROA utilizando os métodos de Borda e Copeland. No primeiro, os fatores 15, 5 e 27 foram os mais bem colocados, ou seja, considerados os mais relevantes pelos respondentes. Os itens 13, 32 e 12 foram os avaliados como os de menor relevância, dentre os 34 fatores avaliados. No de Copeland, o resultado indica que os fatores 15, 5 e 26 foram os mais bem classificados, enquanto os 12, 13 e 32 foram considerados de menor relevância.

\subsection{ANÁLISE COMPARATIVA ENTRE OS RANKINGS}

Para verificar se as ordenações produzidas pelos métodos de Borda e de Copeland são estatisticamente coincidentes ou não, dado que as variáveis não apresentam distribuições normais, utilizou-se os coeficientes não paramétricos de correlação de Spearman (rank correlation) e de Kendall. Segundo Bolboaca e Jäntschi (2006), classifica-se como fraca a associação entre rankings quando o coeficiente de correlação é menor que 0,50.

O coeficiente de correlação de postos de Spearman, frequentemente denotado pela letra grega $\rho$ (rô ou rho), varia entre -1 e 1. Quanto mais próximo estiver destes extremos, maior será a associação entre as variáveis. O sinal negativo da correlação significa que as 
variáveis variam em sentido contrário, isto é, as categorias mais elevadas de uma variável estão associadas a categorias mais baixas da outra variável.

O coeficiente de correlação por postos de Kendall, $\tau$ (tau) é uma medida de associação para variáveis ordinais. A correlação de Kendall entre duas variáveis será elevada se as observações tiverem uma classificação semelhante, comparadas as duas variáveis. Se forem independentes, espera-se que o coeficiente t seja próximo de zero.

Conforme demonstrados na Tabela 5, os coeficientes de Spearman e de Kendall calculados demonstram fraco grau de associação, quando se investiga os 34 fatores juntos, porém indicam existir crescente correlação entre os rankings fornecidos pelos métodos de Borda e Copeland, a medida em que se restringe o número de fatores observados. Torna-se relevante destacar que os índices de correlação aqui utilizados não possuem a pretensão de generalizações estatísticas, visto que não foi calculado o nível de significância.

\begin{tabular}{|l|l|l|l|}
\hline \multicolumn{1}{|c|}{ QTD. FATORES } & \multicolumn{3}{|c|}{10} \\
\hline TESTES & 34 & \multicolumn{3}{|c|}{5} \\
\hline thop & & & 0.9000 \\
\hline thop & & 0.7575 & \\
\hline thop & 0.3482 & & \\
\hline
\end{tabular}

\begin{tabular}{|l|c|c|c|}
\hline \multicolumn{1}{|c|}{ QTD. FATORES } & \multicolumn{3}{|c|}{10} \\
TESTES & 34 & \multicolumn{3}{|c|}{5} \\
\hline Kendall tau T & & & 0.8000 \\
\hline Kendall tau i & & 0.6000 & \\
\hline Kendall tau T & 0.2549 & & \\
\hline
\end{tabular}

Tabela 5 - Comparação dos Coeficientes de Spearman $(\rho)$ e de Kendal $(\tau)$ com diferentes quantidades de fatores

Ao circunscrever a análise apenas aos 10 fatores mais bem classificados, constata-se total intersecção destes fatores em ambos os métodos, ou seja, os 10 fatores mais bem ranqueados pelos métodos de Borda e Copeland são exatamente os mesmos, além de possuírem expressivo grau de correlação, atestado por um $\rho$ de 0,75 e um $\tau$ de 0,60.

Ao considerar apenas os fatores listados como top 5, verifica-se significativo aumento da intensidade de correlação, com $\rho$ de 0,90 e $\tau$ de 0,80, corroborando com a tendência de convergência a medida que se reduz a quantidade de fatores em análise.

\subsection{Ranking Final dos TOP 10 Fatores Mais Relevantes}

A relação dos 10 fatores mais relevantes para a condução de um processo de Transformação Digital, de acordo com a perspectiva dos respondentes desta pesquisa, processado e atestado pelos métodos de Borda e Copeland, está demonstrado na Tabela 6.

Nota-se $100 \%$ de intersecção entre os resultados produzidos por ambos os métodos, e que os fatores 15, 5, 30, 3 e 29 possuem absoluta sobreposição, enquanto os outros 5 têm seu posicionamento levemente modificado, como o par 26 e 27, e a trinca 1, 14 e 16 . Adicionalmente, as dimensões com maior destaque foram: Estratégia (26, 27, 29 e 30) e Liderança (14, 15 e 16). 


\begin{tabular}{|c|c|c|c|c|}
\hline \multicolumn{2}{|c|}{ ITEM CATEGORIA } & FATORES & \multicolumn{2}{|c|}{ BORDA COPELAND } \\
\hline 15 & Lideranç̧a & CEO totalmente compromeitido - percebido como principal patrocinador das transformaaçoes organizacionalis & 1 & 1 \\
\hline 5 & Cliente & Foco em Customer Experience (CX): Cliente é a prioridade e a razzäo do negócio & 2 & 2 \\
\hline 27 & Estratégia & Modelo de negócios revisado/ajustado para competir digitamente & 3 & 4 \\
\hline 26 & Estratégla & Organizaçăo possui uma visăo clara sobre seu posicionamento no futuro & 4 & 3 \\
\hline 30 & Estratégia & Dispöe de Roadmap para conduzirinortear sua Transformaçäo Digital & 5 & 5 \\
\hline 14 & Liderança & CIO máls estratégico - maior envolvimento, a linhamentio e trânsito de TI com as áreas de negócios & 6 & 7 \\
\hline 16 & Liderança & Alta e médila gerênncia com ativa participaçäo e engajamentio digital & 7 & 8 \\
\hline 1 & Cultura & Ambiente organizacional encoraja experimentaçäo, tomada de riscos e aceita falhas (fail-fast/ trydlearn) & 8 & 6 \\
\hline 3 & Cultura & Organizaçäo fomenta mentalidade digital como parte da rotina de trabalho (agenda digital, atuaçăo nas mídias socias) & 9 & 9 \\
\hline & Estratégia & Conhece e monitora o mercado e seus principais competidores (incumbentessstartups) & 10 & 10 \\
\hline
\end{tabular}

Tabela 6 - Relação dos 10 fatores mais relevantes produzida pelos métodos de Borda e Copeland

\subsection{AnÁlise Comparativa Multi-Setor}

Considerando que 9 entre os 10 respondentes possuem experiência e qualificação em três setores específicos (Telecomunicações, Finanças e Varejo), segmentou-se os dados coletados para a elaboração de três novos ranqueamentos, visando avaliar e comparar os top 10 fatores particularizados pela proficiência destes respondentes.

O diagrama de Venn, ilustrado na Figura 2, demonstra as intersecções encontradas entre os três setores. Nesta análise identifica-se que 3 fatores são comuns a todos os setores, 8 surgem da intersecção de pares de setores (Telco-Varejo; Telco-Finanças; VarejoFinanças), enquanto os outros 5 fatores são exclusivos do segmento.

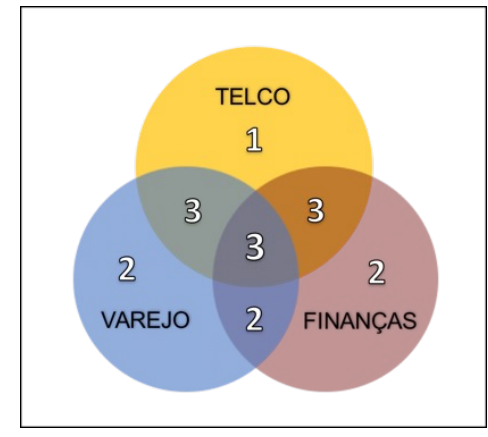

Figura 2 - Intersecção dos 10 fatores melhor ranqueados nos três setores

A união dos top 10 fatores destes três setores revela um total de 16 fatores, ou seja, 6 a mais do que os 10 originalmente identificados antes da segmentação.

A Tabela 7 apresenta a lista destes fatores, e destaca, em negrito, os 6 que emergiram após a segmentação dos dados. Nota-se que a análise multi-setor permite evidenciar duas dimensões não reveladas no ranqueamento anteriormente: Inovação (10 e 11) e Operações (18 e 20), caras aos segmentos de Varejo e Telecomunicações.

Ao confrontar-se este domínio de 16 fatores na perspectiva das duplas Telco-Varejo (T-V), Telco-Finanças (T-F) e Varejo-Finanças (V-F), percebe-se que este último valoriza mais os fatores relacionados à Estratégia, enquanto o dueto Telco-Finanças preza os relativos à Liderança. A primeira dupla, Telco-Varejo, traz uma atenção mais própria para a Inovação e Cultura. 


\begin{tabular}{|c|c|c|c|}
\hline ITEM & CATEGORIA & FATORES RELEVANTES & T.V T.F $\quad$ V.F \\
\hline 1 & Cultura & Ambiente organizacional encoraja experimentação, tomada de riscos e aceita falhas (fail-fast / try\&learn) & \\
\hline 3 & Cultura & Organização fomenta mentalidade digital como parte da rotina de trabalho (agenda digital, atuação nas midias socias) & \\
\hline 5 & Cliente & Foco em Customer Experience (CX): Cliente é a prioridade e a razāo do negócio & \\
\hline 10 & Inovação & Processo ativo de Gestão de inovação (geração, captação, seleção de ideias, recompensa) & TELCO + \\
\hline 11 & Inovação & Organização aberta para identificar novas formas de geração de receita & VAREJO \\
\hline 13 & Liderança & Conselho de Administração com experiência e visão sobre negócios digitais & FINANÇAS \\
\hline 14 & Liderança & $\mathrm{CIO}$ mais estratégico - maior envolvimento, alinhamento e trânsito de TI com as áreas de negócios & \\
\hline 15 & Liderança & CEO totalmente comprometido - percebido como principal patrocinador das transformaçōes organizacionais & \\
\hline 16 & Liderança & Alta e média gerência com ativa participação e engajamento digital & \\
\hline 18 & Operaçōes & Processos de negócios reconfigurados e automatizados para agir com mais agilidade & VAREJO \\
\hline 20 & Operaçōes & Cadeia de Suprimentos bem qualificada, orquestrada e ágil (fornecedores e parceiros com experiência digital) & TELCO \\
\hline 26 & Estratégia & Organização possui uma visão clara sobre seu posicionamento no futuro & \\
\hline 27 & Estratégia & Modelo de negócios revisado/ajustado para competir digitalmente & \\
\hline 28 & Estratégia & Investimentos e recursos necessários são conhecidos e estão orçados & FINANÇAS \\
\hline 29 & Estratégia & Conhece e monitora o mercado e seus principais competidores (incumbentes/startups) & \\
\hline 30 & Estratégia & Dispőe de Roadmap para conduzir/nortear sua Transformação Digital & \\
\hline
\end{tabular}

Tabela 7 - 16 fatores da união dos Top 10 dos setores de Varejo, Telecomunicações e Finanças

\section{CONSIDERAÇÕES FINAIS}

A presente pesquisa teve por objetivo identificar um conjunto de fatores críticos e importantes para a condução de um processo de Transformação Digital nas organizações, e, em seguida, ordená-los visando eleger os 10 fatores de maior relevância no contexto empresarial brasileiro. Foram observados critérios rígidos na escolha bibliográfica utilizada tanto para a fundamentação dos construtos quanto na seleção dos fatores. Procurou-se ainda, empiricamente, revisar e incorporar novos fatores relacionados a contemporânea revolução digital.

Para tal, uma relação de 34 fatores foi constituída, um material de pesquisa desenvolvido e distribuído à experientes especialistas, solicitados a fornecer uma ordenação destes fatores sob a ótica de sua prioridade e relevância na busca de uma efetiva e bemsucedida Transformação Digital. Os dados coletados foram tratados pelos métodos de AMD, mais especificamente os métodos ordinais de Borda, Condorcet e Copeland.

Ao analisar-se os 10 principais fatores gerados pelos métodos de votação de Borda e Copeland, percebe-se que houve $100 \%$ de similaridade entre eles, ou seja, todos os elencados pela contagem de Borda foram integralmente considerados pelo método de Copeland, independentemente da posição ocupada no ranking. Adicionalmente, a alta associação entre os rankings dos dois métodos foi atestada pelos coeficientes de correlação de Spearman e Kendall.

Isto sugere que $100 \%$ dos fatores relacionados como Top 10 - relacionados nas ordenações de ambos os métodos, devem receber especial atenção dos gestores que planejem conduzir um processo de Transformação Digital em suas operações brasileiras. Os 10 fatores identificados como os mais relevantes são:

- CEO totalmente comprometido - percebido como principal patrocinador das transformações organizacionais 
- Foco em Customer Experience (CX): Cliente é a prioridade e a razão do negócio

- Modelo de negócios revisado/ajustado para competir digitalmente

- Organização possui uma visão clara sobre seu posicionamento no futuro

- Dispõe de Roadmap para conduzir/nortear sua Transformação Digital

- CIO mais estratégico - maior envolvimento, alinhamento e trânsito de TI com as áreas de negócios

- Alta e média gerência com ativa participação e engajamento digital

- Ambiente organizacional encoraja experimentação, tomada de riscos e aceita falhas (fail-fast / try\&learn)

- Organização fomenta mentalidade digital como parte da rotina de trabalho (agenda digital, atuação nas mídias sociais)

- Organização conhece e monitora o mercado e seus principais competidores (incumbentes/startups)

Ao avaliar-se as dimensões que acomodam estes fatores, conclui-se que os fatores relativos a Estratégia, Cultura e Liderança devem receber maior atenção dos executivos que aspirem transformações proveitosas. A Figura 3 ilustra a relevância ponderada dos 34 fatores distribuídos em suas oito dimensões.

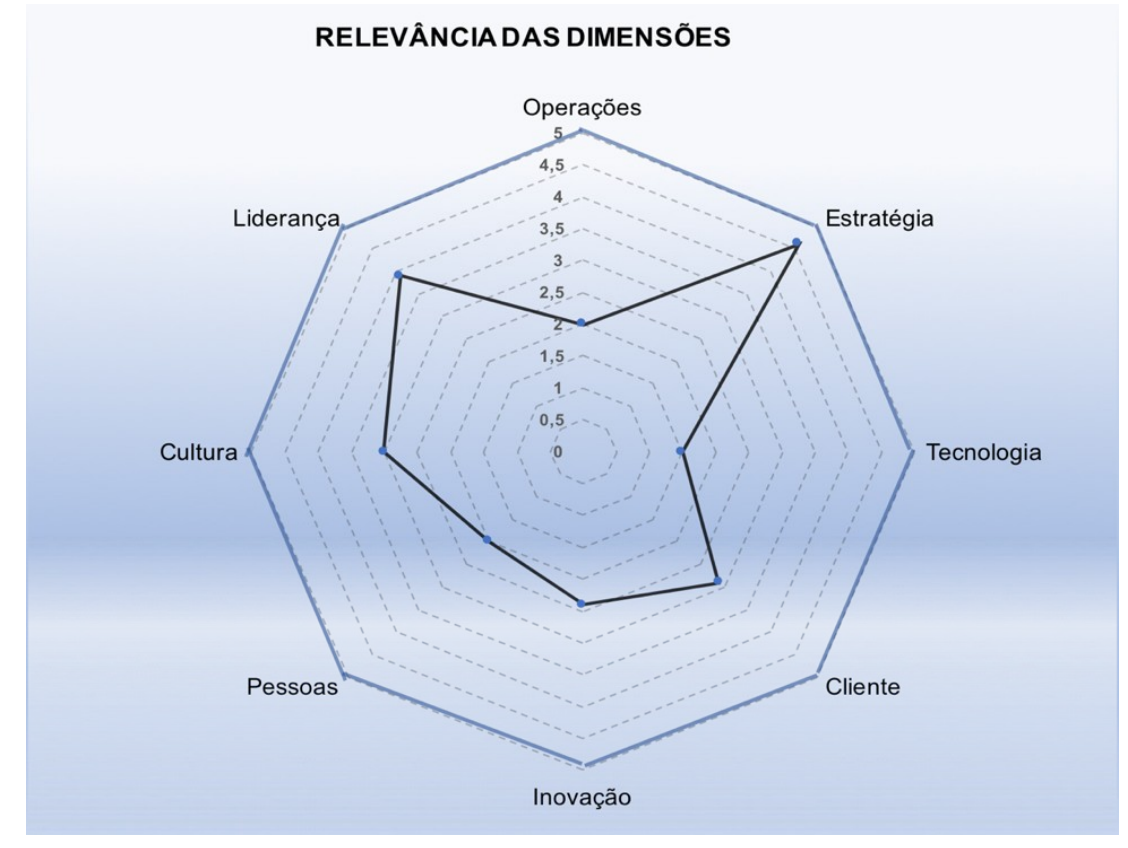

Figura 3 - Importância Relativa das Dimensões utilizadas no processo de Transformação Digital

É interessante sublinhar que o fator de maior destaque, quase uma unanimidade entre os respondentes, foi o que reforça a necessidade de um CEO ativo, comprometido e efetivo patrocinador da jornada transformacional. Na sequência surgem os fatores que ressaltam a importância do Cliente ser tratado como a prioridade do negócio, e de se possuir um modelo de negócios ajustado para competir digitalmente.

Por outro lado, ao contrário do previsto, não se obteve suporte empírico para dar relevo e notoriedade aos fatores orientados à dimensão Pessoas, que invoca a necessidade de se possuir competência e expertise digital. As análises realizadas sugerem também que a dimensão Tecnologia é percebida como coadjuvante, possivelmente como um ingrediente que necessita estar presente apenas para dar suporte à condução da jornada.

A pesquisa proporcionou oportunidade de aprendizado quando à priorização de 
alguns fatores para o processo de Transformação Digital. Apresentou, entretanto, limitações que se referem à forma de coleta de dados, uma vez que além de exigir grande esforço cognitivo dos dez respondentes para ordenar os 34 fatores, possibilita ainda a criação de viés quando da interpretação dos dados, visto que todos atuam no mercado brasileiro como consultores de negócios e/ou fornecedores de serviços de TI.

Por fim, vale ressaltar que com base nos resultados encontrados, as implicações gerenciais para organizações que pretendem conduzir uma Transformação Digital, vão além da priorização do conjunto de fatores aqui revelados. O estudo sugere ainda algumas reflexões sobre o futuro das organizações, tais como:

- Avaliar o custo da inação, pois a percepção tardia da aproximação do fenômeno da disrupção digital pode comprometer a perenidade da organização;

- Considerar que a transformação se dá ao longo do tempo, e não na configuração de um Big Bang, e que a oferta de produtos e serviços do core business devem continuar enquanto se explora novas oportunidades de negócios nas plataformas digitais;

- Certificar-se de que uma estratégia para o futuro começa com a suposição de que o amanhã pode não se assemelhar com o contexto corrente. Envolve a observação de tendências e a realização de constantes experimentos junto aos Clientes.

\section{REFERÊNCIAS BIBLIOGRÁFICAS}

AZHARI, P., FARABY, N., ROSSMANN, A., STEIMEL, B., WICHMANN, K. S. (2014). Digital Transformation Report 2014: neuland GmbH. Editora: WirtschaftsWoche

BARBA-ROMERO, S., POMEROL, J. JC (1997). Decisiones multicritério: Fundamentos Teóricos y Utilización Práctica, Colección de Economía, Universidad de Alcalá.

BIRKINSHAW, J., ZIMMERMANN, A. (2016). How to Adapt to Discontinuous Change? 75th Academy of Management Annual Meeting (AOM) "Opening Governance". Vancouver, British Columbia, Canada.

BOLBOACA, S. D., JÄNTSCHI, L. (2006). Pearson versus Spearman, Kendall’s tau correlation analysis on structure-activity relationships of biologic active compounds. Leonardo Journal of Sciences, 5(9), 179-200.

COLLIN, J., HIEKKANEN, K., KORHONEN, J. J., HALÉN, M., ITÄLÄ, T., HELENIUS, M. (2015). IT leadership in transition-The impact of digitalization on Finnish organizations. Aalto University publication series.

COOK, W. D., SEIFORD, L. M. (1982). On the Borda-Kendall consensus method for priority ranking problems. Management Science, 28(6), 621-637.

GOMES, C. F. S., COSTA, H. G. (2015). Aplicação de métodos multicritério ao problema de escolha de modelos de pagamento eletrônico por cartão de crédito. Production, 25(1), 5468.

GOMES, L. F. A. M., GOMES C. F. S. (2014). Tomada de Decisão Gerencial-Enfoque Multicritério. 5.a edição - Editora Atlas. São Paulo.

GOMES, L. F. A. M., MURY, A. R., GOMES, C. F. S. (1997). Multicriteria ranking with ordinal data. Systems Analysis Modelling Simulation, v.27, 139-146.

GOMES, L.F.A.M., ARAYA, M.C.G., CARIGNANO, C. (2004). Tomada de decisão em cenários complexos. Cengage Learning. São Paulo. 
HENRIETTE, E., FEKI, M., BOUGHZALA, I. (2016). Digital Transformation Challenges. In MCIS (p. 33).

HESS, T., MATT, C., BENLIAN, A., WIESBÖCK, F. (2016). Options for Formulating a Digital Transformation Strategy. MIS Quarterly Executive, 15(2).

HOLOTIUK, F., BEIMBORN, D. (2017). Critical success factors of digital business strategy. The 13th International Conference on Wirtschaftsinformatik.

INNOSIGHT Executive Briefing (2018). 2018 Corporate Longevity Forecast: Creative Destruction is Accelerating. Disponível em http://www.innosigth.com [Acessado em 15 de Abril de 2018].

KHAN, S. (2016). Leadership in the digital age: A study on the effects of digitalisation on top management leadership. (Dissertation). Retrieved from http://urn.kb.se/resolve? urn=urn:nbn:se:su:diva-133809

KIRON, D., KANE, G. C., PALMER, D., PHILLIPS, A. N., BUCKLEY, N. (2016). Aligning the organization for its digital future. MIT Sloan Management Review, 58(1).

LARICHEV, O. I., MOSHKOVICH, H. M. (1995). ZAPROS-LM-A method and system for ordering multiattribute alternatives. European Journal of Operational Research, 82(3).

MORENO Jr., V. D. A., CAVAZOTTE, F. D. S. C. N., Valente, D. (2009). Strategic alignment and its antecedents: a critical analysis of constructs and relations in the international and Brazilian literatures. Journal of Global Information Technology Management, 12(2), 33-60.

PAGANI, M., PARDO, C. (2017). The impact of digital technology on relationships in a business network. Industrial Marketing Management, 67, 185-192.

PICCININI, E., GREGORY, R. W., KOLBE, L. M. (2015). Changes in the ProducerConsumer Relationship-Towards Digital Transformation. In Wirtschaftsinformatik (pp. 1634-1648).

ROGERS, D. L. (2016). The digital transformation playbook: Rethink your business for the digital age. Columbia University Press. New York, NY.

ROY, B., BOUYSSOU, D. (1993). Aide multicritère à la décision: méthodes et cas (p. 695). Paris: Economica.

SAARI, D. G., DONALD, G. (2001). Decisions and elections: explaining the unexpected. Cambridge University Press.

SOARES DE MELLO, M.H.C. Avaliação de Desempenho nas Engenharias: Estudo de Caso UFF. Tese de Mestrado, Engenharia de Produção, Universidade Federal Fluminense, Niterói, 2002.

SOARES DE MELLO, J.C.C.B., GOMES, L.F.A.M., GOMES, E.G., SOARES DE MELLO, M.H.C. Use of ordinal multi-criteria methods in the analysis of the Formula 1 world championship. Cadernos EBAPE.BR, v.3, n.2, 2005b.

VALENTINE, E., STEWART, G. (2015). Enterprise Business Technology Governance: Three competencies to build board digital leadership capability. In System Sciences (HICSS), 48th Hawaii International Conference on (pp. 4513-4522).

WEB PROA Software, software livre para os métodos multicritérios à decisão borda, condorcet e Copeland, Departamento de Engenharia de Produção - UFF(2013), URL https:// www.webproa.com/ 